\title{
Quality of Life in Patients with Stroke
}

\author{
Ketaki Vijay Mandke* and Suvarna Shyam Ganvir \\ D.V.V.P.F's College of physiotherapy, India
}

Submission: September 11, 2017; Published: October 10, 2017

*Corresponding author: Ketaki Vijay Mandke, Final Year BPTH Student, D.V.V.P.F’s College of physiotherapy, Ahmednagar, Maharashtra, India, Tel: 8655245988; Email: ketakimandke9@gmail.com

\begin{abstract}
Background: Stroke is a condition in which damage to brain occurs due to insufficient blood supply to the brain. It can occur in any age, in young age-it can be because of road traffic accident and in elderly or middle aged, it can occur due to risk factors like hypertension. The stroke can be is chemical, hemorrhagic and transient ischemic attack. Major risk factor of stroke can be hypertension, or other factors like diabetes, smoking, lack of exercise etc. Quality of life is the standard of health, comfort and happiness experienced by an individual. The quality of life should be assessed to look for limitation in the functional activities of daily living in patients. Stroke is the leading cause of disability in India. The incidence rate in India is 119-145/100,000 people. In patients with stroke the quality of life is affected mainly due to factors like weakness which leads to a disability where in patient has difficulty in performing daily activities. The patient is not able to come to the position of sitting, standing, balance and postural impairments will be present, there will be reduced functional mobility (e.g. timed get up go test) and there will be more risk of falls. In stroke patients, the quality of life can be measured by using three questionnaires mainly
\end{abstract}

A. Stroke Specific Quality of Life questionnaire (SS-QOL).

B. Short Form 36.

C. Short Form 12.

The stroke specific quality of life questionnaire is chosen as it is specific to the condition.

Aim: The aim of the study is to explore the physical factors affecting quality of life in patients with stroke.

Method and procedure: The study conducted was an observational study carried out in D.V.V.P.F's Medical Hospital. 60 patients were included suffering from sub-acute and chronic stroke. Acute stroke patients were not included as in the acute stage patient's quality of life is low because the stroke has recently occurred. Patients with other neurological conditions like traumatic brain injury, spinal cord injury, Guillean Barre' syndrome and vertebral compression fracture were also excluded as the SS-QOL is a stroke specific measure of assessing quality of life. To carry out the study visit to the hospital was made to contact patients and to assess their quality of life. The patients with stroke were identified and diagnosed on the basis of history, clinical findings weakness, sensor motor impairments, CT scans and MRI reports. A consent form was prepared and consent of every patient or the concerned relative who is participating is taken. The patient was explained about the purpose of the study which is to know the activities of patient which are affected by using SS-QOL questionnaire. The SS-QOL questionnaire was used to assess the quality of life. The components of the questionnaire were explained to the patient and the score is noted down as per patients' answer to a question.

Result: Total demographic of males and female participated in the study was $51.6 \%$ and $48.3 \%$ respectively. Males in the younger age group of $35-50$ were more i.e. $75 \%$ and in the older age group of $51-70 \%$ were $25 \%$ and it is vice a versa for females $45.8 \%$ and $54.1 \%$ respectively. Study showed that when scored using SS-QOL, there were four domains in which patients have more difficulty viz. work and productivity, self-care, mobility and upper extremity function. Co-relation was then found out of side of affection and the scores of affected domains, work and productivity $(\mathrm{p}=0.036)$ and mobility $(0.039)$ this were showed to be more significantly affected than others, self-care $(\mathrm{p}=0.22)$ and upper extremity function $(\mathrm{p}=0.42)$. Further correlation was made to note the difference in the ability to perform activities of self-care, mobility, upper extremity function and work and productivity in people with different levels of ambulation. For people who stand and walk independently and those who can't stand and walk there is significant difference in the abilities to perform domains of work and productivity, self-care, upper extremity function, mobility and overall score of SS-QOL $(\mathrm{p}<0.001)$. For the component of self-care $(\mathrm{p}<0.001)$, mobility ( $<<0.01)$ and upper extremity function $(\mathrm{p}<0.01)$, the ability of people with highest level of ambulation i.e. independent and for those who need ambulatory support the difference is quite significant. When scores of these four domains of males and females are compared, it showed that there is no much difference in the abilities to perform those functions, there is no significant difference in the quality of life; work and productivity ( $\mathrm{p}=0.48)$, self-care ( $p=7.52)$, upper extremity function $(p=0.755)$, mobility $(p=0.240)$ and total score $(p=0.33)$. Same result was obtained for comparisons between two age groups, 35-50 and 51-70, work and productivity ( $\mathrm{p}=0.067)$, self-care $(\mathrm{p}=0.095)$, mobility $(\mathrm{p}=0.07)$, upper extremity function $(\mathrm{p}=0.25)$ and total score $(\mathrm{p}=0.1)$.

Conclusion: Study concludes that components which affect quality of life are work and productivity, mobility, upper extremity function and self- care.

Keywords: Stroke; Quality of life; Domains 


\section{Introduction}

Stroke is defined by World Health Organization as a clinical syndrome consisting of rapidly developing clinical signs of focal or global disturbance of cerebral function lasting more than 24 hours or leading to death with no apparent cause other than a vascular origin [1]. It is a major public health issue causing morbidity and mortality amongst people [2]. Morbidity and mortality tends to be higher in long term stroke survivors i.e. in sub-acute and chronic stage of stroke. Acute stroke is stated by sudden onset stroke whereas chronic is stroke of indefinite or prolonged duration and sub-acute stroke is stated as recent onset stroke. Patients who survive a stroke often experience a reduced health related quality of life. Quality of life is a standard of health, comfort and happiness experienced by an individual. Measuring quality of life is an important aspect to look for functional limitations of patients, to assess quality of service, need for health care and the effectiveness of intervention. This reflects importance of how patient feels and how satisfied he is with the treatment [3]. QOL assessment includes at least 4 dimensions: physical, functional, psychological, and social health. The physical health dimension refers to disease-related symptoms. Functional health comprises self-care, mobility and the capacity to perform various families and work roles. Psycho- logical dimension includes cognitive and emotional functions (e.g. vascular dementia and post stroke depression) and subjective perceptions of health and life satisfaction. Social dimension includes social and familial contacts [4]. Quality of life can be measured by using scales (barthel index, rankin scale) and questionnaires (e.g. For stroke- short form 36 , short form 12, stroke specific quality of life questionnaire) [4]. For assessment of quality of life in stroke patients use of questionnaire is widely done to cover all the dimensions of quality of life. The stroke specific quality of life questionnaire is a well -known, standardized, diseased- specific measure to assess health related quality of life in stroke patients. It consists of 49 items in about 12 domains (energy, family roles, language, mobility, mood, personality, self- care, social roles, thinking, upper extremity function, vision and work and productivity) [5]. This scale is chosen as it covers all the 4 dimensions of quality of life viz. physical, functional, psychological and social health. Study is being done to explore physical factors which affect quality of life, to assess overall quality of life in stroke patients and to know about factors other than physical factors that can affect quality of life.

\section{Method and Material}

Sample- Study was carried out for 9 months from August 2016 to April 2017. Study was carried out including 31 patients out of which 16 were males and 15 were females. Sample size calculated based on the formula of calculating proportion which uses prevalence of stroke patients in the hospital. Patients from Dr. Vitthalrao Vikhe Patil medical hospital and Physiotherapy OPD were taken for the study. Patients admitted in wards suffering from stroke were studied for assessing their quality of life. Diagnosis was done by looking at clinical and radiological records. People with stroke duration of more than 1 month were included for the study i.e. people suffering from sub-acute and chronic stroke to obtain correct measure of quality of life as in acute stage patient tends to be more dependent due to severe weakness. Observational study was carried out by visiting hospital and OPD. Patients were informed about the study and why it is being carried out. Patients were told that assessing quality of life will help to set a proper treatment protocol for them and it will lead to a gradual return to functional activities. Patients' consent or consent from their respective relative was obtained before including them for study. Data collected based on age, sex, dominant side, side of affection, co-morbid conditions and level of ambulation. Questionnaire-The survey form was written according to a validated instrument, Stroke Specific Quality of Life Scale (SS-QOL) questionnaire 12. It consisted of 49 questions grouped in 12 domains (energy, family role, language, mobility, mood, personality, self- care, social role, thinking, memory, vision, upper extremity function, work and productivity). This scale was chosen as it is more specific to the condition. Each domain was rated on a 1-5 point Lykert type scale, according to the degree of agreement with a particular statement, ranging from full agreement (1) to full disagreement (5). The domain results were registered on a score-sheet, and later summed-up to get the global result (maximal score 260 points). Lower scale results indicated worse condition and higher patient's dependency in daily life activities.

\section{Result}

After collecting all the data, physical factors which affect quality of life and patient has worse scores of those are identified (Table 1). Then percentage values are calculated by age and gender wise distribution and 4 domains in which patient has more difficulty viz. self-care, work and productivity, mobility, upper extremity function and total score of all the domains from the SS-QOL questionnaire were correlated with side of affection (dominant side affection and non- dominant side affection), age (younger i.e. 31-50 and older i.e. 51-70 age) and the level of ambulation of the patient i.e. (whether patient is unable to walk, needs support for walking and walks without support) (Table 2). Table 3 Study shows there is no as such significant difference between all the 4 components for dominant side affection and non-dominant side affection and work and productivity and mobility being on the slight significant side. For other 2 domains i.e. upper extremity function and self -care people tend to use unaffected extremity for that causing no significant difference. Table 4 Significant difference is obtained for individuals those who are able to stand and walk independently vs. those who cannot stand and walk, as individuals who cannot stand and walk could not perform any of the work. For rest of the two comparisons i.e. people who are able to stand and walk independently vs. those who stand and walk with support and stand and walk with support vs. those 


\section{Journal of Yoga and Physiotherapy}

who are unable to stand and walk. Table 5 Significant difference is obtained statistically for all the 3 comparisons and for 1st two, difference being more significant. Patients who need support for standing and walking cannot perform cooking food, bathing and toilet activities efficiently and those who cannot stand and walk are unable to perform any of the self- care activity. Table 6 Significant difference is obtained for comparisons of standing and walking independently vs. with support and standing and walking independently vs. unable to stand and walk, later being statistically more significant.
Table 1: It explains the domains of SS-QOL which score worse. Domains of work and productivity, self- care, upper extremity function and mobility score worse compared to others.

\begin{tabular}{|c|c|c|}
\hline Domains & Mean & P Value \\
\hline $\begin{array}{c}\text { Work and } \\
\text { productivity }\end{array}$ & 7.774 & $<0.0001$ \\
\hline Self- care & 16.35 & 0.0038 \\
\hline $\begin{array}{c}\text { Upper extremity } \\
\text { function }\end{array}$ & 16.35 & 0.0048 \\
\hline Mobility & 18.77 & 0.0005 \\
\hline
\end{tabular}

Table 2: Describes the demographics of study population i.e. in the age group of 35-50 and 51-70 percentage of males and females, people with dominant and non-dominant side affection, people with stroke duration of 1 to 6 months, 6 months to 1 year and more than 1 year, people with comorbid conditions and people with no co-morbid conditions and according to gender, percentage of total males and females, males and females in the age group of 35-50 and 51-70, males and females with dominant side and non-dominant side affection males and females with stroke duration of 1-6 months, 6months-1yr and more than 1 year, males and females with co-morbid conditions and no co-morbid conditions.

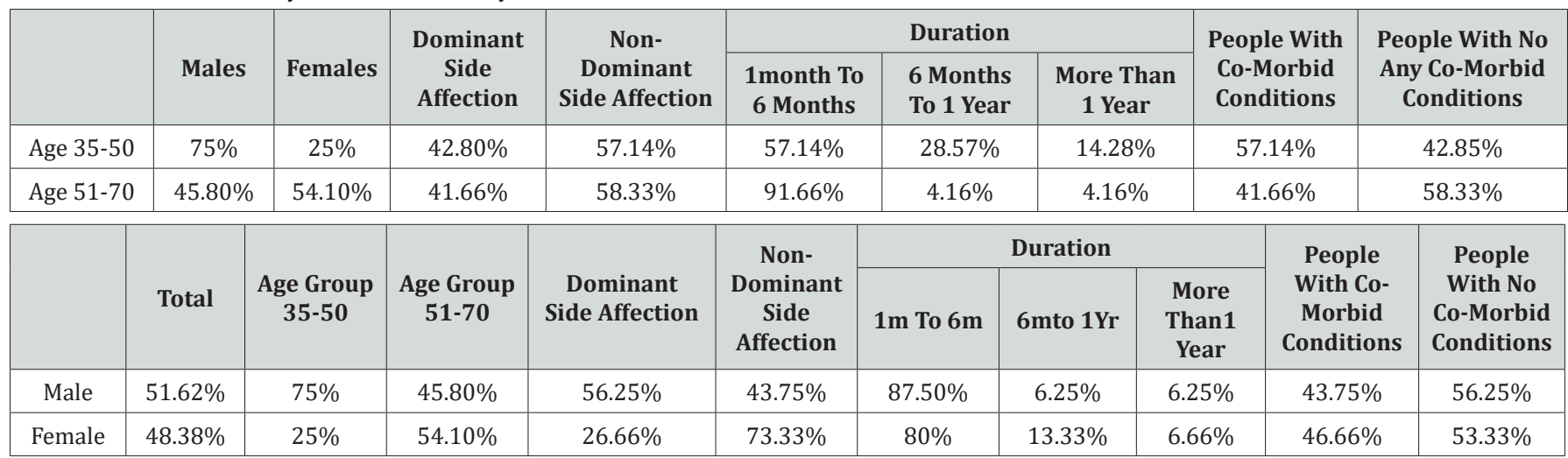

Demographics of study population Age-group wise distribution.

Table 3: Describes the relation of above 4 domains with the side of affection of the patient. It is looked for to know whether any significant difference occurs for people with dominant side affection and non- dominant side affection.

\begin{tabular}{|c|c|c|c|}
\hline Components & Dominant Side Affection & Non Dominant Side Affection & P Value \\
\hline Work and productivity & $9+3.266$ & $6.88+2.083$ & 0.036 \\
\hline Self-care & $18.077+7.772$ & $15.111+6.388$ & 0.2211 \\
\hline Mobility & $23.30+8.645$ & $15.111+9.436$ & 0.039 \\
\hline Upper extremity function & $17.69+8.92$ & $15.388+6.395$ & 0.423 \\
\hline Overall score SS-QOL & $179.69+40.421$ & $156.5+38.28$ & 0.1147 \\
\hline
\end{tabular}

Table 4: Work and productivity of individuals who are able to stand and walk stand and walk with support and unable to stand and walk is compared

\begin{tabular}{|c|c|c|}
\hline Work and Productivity & Mean Rank Difference & P Value \\
\hline Stand and walk independently vs. with support & $2.056>0.05$ \\
\hline $\begin{array}{c}\text { Stand and walk independently vs. unable to } \\
\text { stand and walk }\end{array}$ & 4.375 & $* * * \mathrm{p}<0.001$ \\
\hline $\begin{array}{c}\text { Stand and walk with support vs. unable to } \\
\text { stand and walk }\end{array}$ & 2.319 & Ns p $>0.05$ \\
\hline
\end{tabular}

Table 5: Comparison of the self- care domain is made between patients who stand and walk independently vs. those who need support, patients who stand and walk independently vs. those who are unable to stand and walk and patients who need support for standing and walkingvs. who cannot stand and walk.

\begin{tabular}{|c|c|c|}
\hline Self Care & Mean Rank Difference & P Value \\
\hline Stand and walk independently vs. with support & 7.556 & $* * *$ p $<0.001$ \\
\hline $\begin{array}{c}\text { Stand and walk independently vs. unable to } \\
\text { stand and walk }\end{array}$ & 13.375 & $* *$ p $<0.001$ \\
\hline $\begin{array}{c}\text { Stand and walk with support vs. unable to } \\
\text { stand and walk }\end{array}$ & 5.819 & $* \mathrm{p}<0.05$ \\
\hline
\end{tabular}




\section{Journal of Yoga and Physiotherapy}

Table 6: Describes the comparisons made between the scores of mobility component of patients who stand and walk independently vs. stand and walk with support, people who stand and walk independently vs. those who cannot stand and walk and people who stand and walk with support vs. those who cannot stand and walk.

\begin{tabular}{|c|c|c|}
\hline Mobility & Mean Rank Difference & P Value \\
\hline Stand and walk independently vs. with support & 11.671 & $* *$ p $<0.01$ \\
\hline $\begin{array}{c}\text { Stand and walk independently vs. unable to } \\
\text { stand and walk }\end{array}$ & 19.393 & $* * 0.001$ \\
\hline $\begin{array}{c}\text { Stand and walk with support vs. unable to } \\
\text { stand and walk }\end{array}$ & 7.722 & Ns $\mathrm{p}<0.05$ \\
\hline
\end{tabular}

Table 7: Describes comparisons of scores of upper extremity function domain between patients standing and walking status. Significant difference is obtained for patients who stand and walk independently vs. those who cannot and lesser significant difference was obtained for those who stand and walk independently vs. with support.

\begin{tabular}{|c|c|c|}
\hline Upper Extremity Function & Mean Rank Difference & P Value \\
\hline Stand and walk independently vs. with support & 8.175 & $* *$ p $<0.01$ \\
\hline $\begin{array}{c}\text { Stand and walk independently vs. unable to } \\
\text { stand and walk }\end{array}$ & 13.79 p $<0.001$ \\
\hline Stand and walk with support & 5.611 & Ns $\mathrm{p}>0.05$ \\
\hline
\end{tabular}

Table 8: In this, comparison of total scores of all the domains of SS-QOL questionnaire is made in between patients' walking status. Significant difference statistically is obtained for all the three comparisons. Difference between stand and walk independently vs. with support and stand and walk independently vs. unable to stand and walk is quite more significant. As patient tends to be more dependent if his walking status is lower.

\begin{tabular}{|c|c|c|}
\hline Overall Score SS-QOL & Mean Rank Difference & P Value \\
\hline Stand and walk independently vs. with support & 7.556 & $* *$ p $<0.001$ \\
\hline $\begin{array}{c}\text { Stand and walk independently vs. unable to } \\
\text { stand and walk }\end{array}$ & 13.375 & $* 0.001$ \\
\hline $\begin{array}{c}\text { Stand and walk with support vs. unable to } \\
\text { stand and walk }\end{array}$ & 5.819 & $*$ p $<0.05$ \\
\hline
\end{tabular}

Table 9: Correlation between scores of above mentioned four domains and the overall score of SS-QOL in younger (35-50) and older (51-70) is shown to be non-significant. Domains of work and productivity, self- care and mobility are shown to be slightly more significant as compared to others.

\begin{tabular}{|c|c|c|c|}
\hline Components & Age $\mathbf{3 5 - 5 0}$ & Age 51-70 & P Value \\
\hline Work and productivity & $9.5+3.251$ & $7.375+2.568$ & 0.0674 \\
\hline Self -care & $20.25+5.365$ & $15.42+7.27$ & 0.0953 \\
\hline Mobility & $24.875+5.866$ & $17.04+10.28$ & 0.0708 \\
\hline Upper extremity function & $19.375+7.463$ & $15.71+7.82$ & 0.255 \\
\hline Overall score SS-QOL & $188.12+36.48$ & $160.04+40.30$ & 0.103 \\
\hline
\end{tabular}

Table 10: Shows correlation between scores of above mentioned four domains and the overall score of SS-QOL for both males and females. It comes out to be non-significant i.e. there is no significant difference. Quality of life is does not differ significantly for males and females.

\begin{tabular}{|l|l|l|l|}
\hline Components & Males & Females & P Value \\
\hline Work and productivity & $8.12+53.384$ & $7.42+2.063$ & $0.4808(\mathrm{NS})$ \\
\hline Self-care & $16.75+6.894$ & $15.93+7.4$ & 7.5279 (NS) \\
\hline Mobility & $20.81+9.57$ & $16.6+10.02$ & 0.2413 (NS) \\
\hline Upper extremity function & $16.75+8.062$ & $15.93+7.67$ & $0.7751(\mathrm{NS})$ \\
\hline Overall score SS-QOL & $172.93+39.082$ & $158.8+41.21$ & $0.3350(\mathrm{NS})$ \\
\hline
\end{tabular}

\section{Discussion}

Study showed four physical factors which affect quality of life viz. work and productivity $(<0.0001)$, mobility $(0.0005)$, selfcare (0.0038) and upper extremity function (0.0048). Similar study done to measure quality of life and urban area supports this finding of mobility and work and productivity being more affected. Study done in Turkish stroke survivors suggests upper extremity function being affected (0.19). Another study done in Malawi by [6] supports the finding of self- care domain being affected $(0.0024)$. This study shows that there were $51.6 \%$ males and $48.6 \%$ females, which is relevant to that of the study of quality of life among stroke survivors evaluated 1 year done by Artal J [4], where $55.4 \%$ males and $46.4 \%$ females were included (Table 4-7). We found out that there were more males in the younger age 
group of 35-50 i.e. 75\% and more females in the older age group of 51-70 suffered with stroke. In this study, there were more people with non-dominant side affection, i.e. in the younger age group, $57.14 \%$ and in the older age group 58.3\%. This finding is relevant to that of the study health related quality of life in first ever stroke patients done by [7] where $58 \%$ people have non-dominant side involvement. People with co-morbid conditions were found to be less in the older age group in this study (41.6\%), whereas in younger age group (57.14\%) it is more (Table 8). If gender wise distribution is considered, more no. of males and females has no any co-morbid conditions, $56 \%$ and $53 \%$ respectively. In the similar study of health related quality of life in first ever stroke patients [6-10], they found out more no. of people have associated co-morbid conditions. Physical factors which are more affected and those which worsen quality of life are found to be work and productivity, self- care, mobility, upper extremity function. These findings are similar to other 2-3 studies viz (Table 9). The ideal measurement of quality of life in post stroke patients: an urban study by Samsiah $[7,8,11,12]$, determinants of disease specific health related quality of life in Turkish stroke survivors by Safaz J [9], quality of life after first ever stroke; an interview based study from Blantyre, Malawi by [10-15]. But study showed that, there is no significant difference between scores of these components, in people with dominant and non-dominant side affection (work $\mathrm{p}=0.036$, self-care $\mathrm{p}=0.22$ mobility $\mathrm{p}=0.039$, upper extremity function $\mathrm{p}=0.42$ ), people in younger and older age group (work $\mathrm{p}=0.067$, self- care $\mathrm{p}=0.095$, mobility $\mathrm{p}=0.0$ and for males and females [16-20] (Table 10).

\section{Conclusion}

Study concludes that components which affect quality of life are work and productivity, mobility, upper extremity function and self- care.

\section{Acknowledgement}

We are thankful to the principal and ethical committee of our college for providing helpful suggestions, staff of the neurosciences department and peer students for their valuable suggestions and help during the study.

\section{References}

1. Bonita R (1992) Epidemiology of stroke. Lancet 339(8789): 342-344.

2. Vrodoljak D, Rumboldt M (2008) Quality of life after stroke in Croatian patients. Coll Antropol 32(2): 355-359.

3. Carr AJ, Gibson B, Robinson PG (2001) Is quality of life determined by expectations or experience? BMJ 322 (7296): 1240-1243.

4. Carod Artal J, Egido JA, González JL, Varela de Seijas E (2000) Quality of life among stroke survivors evaluated 1 year after stroke: Experience of a Stroke unit. Stroke 31(12): 2995-3000.
5. Post MW, Boosman H, Van Zandvoort MM, Passier PE, Rinkel GJ, et al (2010) Development and validation of a short version of the strokespecific quality of life scale. J Neurol Neurosurg Psychiatry 82(3): 283286.

6. Heikinheimo T, Chimbayo D (2015) Quality of life after first-ever stroke: An interview-based study from Blantyre, Malawi. Malawi Med J 27(2): 50-54.

7. Gurcay E, Bal A, Cakci A (2009) Health-related quality of life in firstever stroke patients. Ann Saudi Med 29(1): 36-40.

8. Samsiah M, Das S, Chee SY, Rashidah R, Siti H, et al. (2011) The ideal measurement of the quality of life in post stroke patients: an urban study. Clin Ter 162(3): 209-215.

9. Hsueh IP, Jeng JS, Lee Y, Sheu CF, Hsieh CL, et al. (2011) Construct validity of the stroke-specific quality of life questionnaire in ischemic stroke patients. Arch Phys Med Rehabil 92(7): 1113-1118.

10. Safaz İ, Kesikburun S, Adigüzel E, Yilmaz B (2016) Determinants of disease-specific health-related quality of life in Turkish stroke survivors. Int J Rehabil Res 39(2): 130-133.

11. Jönsson AC, Lindgren I, Hallström B, Norrving B, Lindgren A, et al. (2005) Determinants of quality of life in stroke survivors and their informal caregivers. Stroke 36(4): 803-808.

12. Sturm JW, Donnan GA, Dewey HM, Macdonell RA, Gilligan AK, et al. (2004) Quality of life after stroke: the north east Melbourne stroke incidence study(NEMESIS). Stroke 35(10): 2340-2345.

13. Niemi ML, Laaksonen R, Kotila M, Waltimo O (1988) Quality of life 4 years after stroke. Stroke 19(9): 1101-1107.

14. Tengs TO, Yu M, Luistro E (2001) Health-Related Quality of life after stroke a comprehensive review. Stroke 32(4): 964-972.

15. Kauhanen ML, Korpelainen JT, Hiltunen P, Nieminen P, Sotaniemi KA, et al. (2000) Domains and determinants of quality of life after stroke caused by brain infarction. Arch Phys Med Rehabil 81(12): 1541-1546.

16. Williams LS, Weinberger M, Harris LE, Biller J (1999) Measuring quality of life in a way that is meaningful to stroke patients. Neurology 53(8): 1839-1843.

17. Visser Meily JM, Rhebergen ML, Rinkel GJ, van Zandvoort MJ, Post MW, et al. (2009) Long term health related quality of life after aneurysmal sub arachnoid haemorrhge: relationship with psychological symptoms and personality characteristics. Stroke 40(4): 1526-1529.

18. Katati MJ, Ramajo SS, García MP, Sánchez Jofré MM, Lopez RV, et al. (2007) Description of quality of life and its predictors in patients with aneurysmal sub arachnoid haemorrhage. Cerebrovasc 24(1): 766-773.

19. Owolabi MO (2008) Determinants of health-related quality of life in Nigerian stroke survivors. Trans R Soc Trop Med Hyg 102(12): 12191225.

20. Madden S, Hopman WM, Bagg S, Verner J, O'Callaghan CJ, et al. (2006) Functional status and health-related quality of life during inpatient stroke rehabilitation. Am J Phys Med Rehabil 85(10): 831-838. 


\section{Your next submission with Juniper Publishers will reach you the below assets}

- Quality Editorial service

- Swift Peer Review

- Reprints availability

- E-prints Service

- Manuscript Podcast for convenient understanding

- Global attainment for your research

- Manuscript accessibility in different formats ( Pdf, E-pub, Full Text, Audio)

- Unceasing customer service

Track the below URL for one-step submission https://juniperpublishers.com/online-submission.php 